\title{
Perspectives of specialists and family physicians in interprofessional teams in caring for patients with multimorbidity: a qualitative study
}

\author{
Pauline Boeckxstaens MD PhD, Judith Belle Brown PhD, Sonja M. Reichert MD MSc, \\ Christopher N.C. Smith MD, Moira Stewart PhD, Martin Fortin MD MSc
}

\section{Abstract}

Background: Patients with multimorbidity often require services across different health care settings, yet team processes among settings are rarely implemented. We explored perceptions of specialists and family physicians collaborating in a telemedicine interprofessional consultation for patients with multimorbidity to better understand the value of bringing physicians together across the boundaries of health care settings.

Methods: This was a descriptive qualitative, interview-based study. Physicians who had previously participated in the Telemedicine Interprofessional Model of Practice for Aging and Complex Treatments (Telemedicine IMPACT Plus [TIP] Program) were invited to participate and asked to describe their experience of being a member of the program. Interviews were conducted from March to May 2016. We conducted an iterative and interpretive process using both individual and team analysis to identify themes.

Results: There were 15 participants, 9 specialists and 6 family physicians. Three themes emerged in the analysis: creating new perspectives on care for patients with multimorbidity by sharing knowledge, skills and attitudes; the shift from a consultant model to an interprofessional team model (allowing a window into the community, extending discussions beyond the medical model and focusing on the patient's health in context); and opportunities for learners, including learning about interprofessional collaboration and gaining exposure to a real-world model for caring for people with multimorbidity in outpatient settings.

Interpretation: Family physicians and specialists participating in a TIP Program believed the program improved their knowledge and skills, while also serving as an effective care delivery strategy. The findings also support that learners require more exposure to nontraditional consultant models in order to care for patients with multimorbidity effectively.

I ncreasingly, people are experiencing multiple chronic conditions. Together with the rise in multimorbidity and the increasing complexity of health care, there is often an exponential increase in the number of health care professionals involved in the patient's care. ${ }^{1}$ In 1 study, patients saw 4-9 professionals regularly. ${ }^{2}$ Some patients experience concerns about multiple appointments, a loss of continuity, inadequate and conflicting information, communication problems with and among clinicians, and lack of access to specialist care. ${ }^{3}$

One possible solution to these challenges is interprofessional teams, which can contribute to both quality of care and cost control. $^{4-7}$ Exploring the experiences of providers working in teams has provided valuable insights into the key features of successful interprofessional teamwork. ${ }^{8,9}$ However, most research in this field has focused on primary health care teams or teams collaborating within hospitals or residential settings. ${ }^{10,11}$
People with multimorbidity require care from providers across settings, which often include primary care, secondary care and community care. Because clinical care is often organized according to the care setting, team processes that extend beyond these traditional boundaries are rarely implemented. ${ }^{12}$ Studies examining a variety of settings including oncology, palliative care, pediatrics and memory clinics have shown that the interfaces between primary and secondary care

Competing interests: None declared.

This article has been peer reviewed.

Correspondence to: Pauline Boeckxstaens, Pauline.boeckxstaens@ ugent.be

CMAJ Open 2020. DOI:10.9778/cmajo.20190222 
are fraught with challenges to effective teamwork. ${ }^{13-15}$ Often, primary care and specialist physicians do not have a clear understanding of each other's skill sets and responsibilities, and experience challenges in delivering timely and appropriate communication.

Some of these barriers can be removed when the quality of the relationships between primary and secondary providers is improved, including shared leadership, collaborative decisionmaking and mutual respect. ${ }^{16,17}$ Supporting interprofessional collaboration throughout both primary care and specialist education and training is important. ${ }^{18}$ Although several professional bodies have recommended interprofessional collaboration as a core competence, ${ }^{19-21}$ health care providers are frequently left with unstructured and implicit learning that often happens only during forced interactions. ${ }^{22}$ Information is still lacking on how interdisciplinary teamwork can be best achieved.

Providers in practice are developing and implementing innovative strategies to address the challenges of interprofessional care for patients with multimorbidity. One such strategy is the Telemedicine Interprofessional Model of Practice for Aging and Complex Treatments, called the Telemedicine IMPACT Plus (TIP) Program, which provides a model of interprofessional primary care consultation for these patients. We explored the perceptions and experiences of specialists and family physicians collaborating in a TIP Program with the aim of better understanding the benefits of working together across the boundaries of different health care settings.

\section{Methods}

\section{Design}

We used a qualitative descriptive approach to explore the role of specialists participating in an innovative model of a primary health care interprofessional team, the TIP Program. ${ }^{23-25}$ The findings here are 1 aspect that emerged during the qualitative component of the Patient-Centred Innovations for Persons with Multimorbidity (PACE in MM) project. ${ }^{26}$

\section{Participant recruitment}

Telemedicine IMPACT Plus Program leads recruited a purposive sample of family physicians and specialists who were current members of 1 of the 4 TIP Programs in place in Toronto at the time of data collection. Participants were contacted by telephone or email to confirm participation. Informed consent was obtained and confidentially was assured.

\section{Telemedicine IMPACT Plus Program}

The TIP Program synchronously connects patients and their primary care physicians by telemedicine in a real-time interprofessional case consultation focused on what is most important to the patient. ${ }^{27}$ The TIP Program team is composed of family physicians, specialists from psychiatry and internal medicine, a social worker, a pharmacist, a home and community care coordinator and other professionals (e.g., occupational therapist, dietitian), based on the patient's needs. There is a dedicated TIP Program registered nurse who meets with the family physician and the patient in advance to prioritize the issues most important to the patient. The team consultation with the patient lasts from 1.5 to 2 hours.

\section{Data collection}

The core research team included a female clinician scientist in family medicine (P.B., a postdoctoral fellow), a female senior scientist with social work background and experience in qualitative methods (J.B.B.), a female clinician scientist in family medicine (S.M.R.) and 2 research assistants, 1 male and 1 female. Semistructured individual interviews were conducted between March and May 2016 by P.B., J.B.B., S.M.R. and the 2 research assistants at the participants' practice location. Participants were asked to describe their experience of being a member of the TIP Program. The interviews lasted 30-60 minutes and were audiotaped and transcribed verbatim. Field notes were written after the interview.

\section{Data analysis}

The data analysis was both iterative and interpretive. For the first phase of analysis, each transcript was reviewed and coded individually by P.B., J.B.B. and S.M.R. to determine key concepts emerging from the data. Next, meeting as a team, the reviewers examined their independent coding, culminating in the initial coding template. This process was repeated until all the interviews were analyzed, the coding template was deemed comprehensive and complete, and data sufficiency had been achieved. Once the main themes and subthemes had been input into NVivo 10 (QSR International), P.B., J.B.B. and S.M.R. reviewed the data to identify the overarching themes and exemplar quotes.

The data reported in this paper reflect the participants' spontaneous comments and reflections during data collection and were not in response to a specific question, nor were they the main objective of this study. The research team members who collected and analyzed the data had no prior relationship with the participants.

We ensured the trustworthiness and credibility of the analysis by using verbatim transcripts, independent and team analysis, and field notes. In a commitment to reflexivity, we considered how the researchers' professional backgrounds (e.g., social work, family medicine, internal medicine, epidemiology), could influence the findings, particularly during the analysis phase.

\section{Ethics approval}

Ethics approval was received from the Health Sciences Research Ethics Board of Western University.

\section{Resullts}

The sample comprised 15 participants, 9 specialists and 6 family physicians (Table 1 ). 


\begin{tabular}{|lc|}
\hline \multicolumn{2}{|l|}{ Table 1: Characteristics of participants } \\
\hline Characteristic & $\begin{array}{c}\text { No. of participants* } \\
n=15\end{array}$ \\
\hline Age, yr, mean (range) & $46(34-65)$ \\
\hline Gender & 8 \\
\hline Female & 7 \\
\hline Male & \\
\hline Specialty & 2 \\
\hline \begin{tabular}{l} 
Geriatrician \\
\hline Psychiatrist
\end{tabular} \\
\hline $\begin{array}{l}\text { General internist } \\
\text { Family physician }\end{array}$ \\
\hline Years of practice, mean & 6 \\
\hline $\begin{array}{l}\text { Years of involvement with TIP Program, } \\
\text { range }\end{array}$ & 13 \\
\hline $\begin{array}{l}\text { Note: TIP = Telemedicine IMPACT Plus. } \\
{ }^{*} \text { Except where noted otherwise. }\end{array}$ \\
\hline
\end{tabular}

Three overarching themes emerged from the data: creating new perspectives on care for patients with multimorbidity by sharing knowledge, skills and attitudes; the shift from a consultant model to an interprofessional team model; and opportunities for learners in an interprofessional outpatient team setting. Illustrative quotes for each theme are provided in Table 2.

\section{Creating new perspectives on care for multimorbidity by sharing knowledge, skills and attitudes}

All of the participants expressed the value of learning from other team members through a transfer of knowledge, skills and experience.

I learn a lot from hearing other health care professionals and their take on some of the patient's problems. (Psych 07)

Working in an interprofessional team enhanced their understanding of the unique contributions of other team members. Participants described how collaborating as a team validated the complexity of the patient's situation and the need to consider various aspects contributing to the patient's challenges. Collaborating together as a team provided added value, with a shift from a single disease focus to an exploration of the various components of the patient's multimorbidity. The specialist participants explained the difference between receiving a case summary versus hearing and discussing the patient's situation in an interprofessional team setting, which provided richer information.

Another key benefit of the interprofessional team was the opportunity to discuss various aspects of the patient's problems from different interprofessional perspectives. Participants described engaging the patient with an interprofessional team of providers at 1 time, in 1 location, as synergistic. It was felt that, for this to occur successfully, team members had to have a well-developed and strong professional identity.

\section{Moving away from a consultant model to an interprofessional team model}

Specialist participants articulated how the interprofessional model based in primary care helped them to understand the patient's experiences outside the walls of the hospital. The experience provided a window into the community, encouraging them to try to understand all facets of the patient's life. This helped move the physicians from an expert role to focus on providing patient-centred care.

Because the environment is present in the picture [telemedicine], people are asking more questions about that kind of stuff than I am used to seeing. (GIM 03)

While adopting this interprofessional model for patients with multimorbidity, specialists were actively considering how care could be best provided and supported.

This is really about brainstorming with this patient and family physician about how can we better meet their needs. (FP 12)

Being a member of the interprofessional team increased the specialists' awareness of and respect for the family physician's role and consequently enabled them to provide relevant recommendations within the context of primary care. Participating in the interprofessional team exposed the specialist participants to a different practice model that required them to relinquish the traditional consultation model, therefore moving them to a more shared-care collaborative practice. Specialists also described how they could be more accessible to this patient population in comparison to the traditional consultation model. Participants noted how working on this interprofessional team required specialist to extend beyond the traditional medical model and alter their focus from labelling the disease to be more patient-centred by understanding the patient's issues and needs.

\section{Opportunities for learners}

Participants noted how the TIP Program addresses important gaps in medical education. First, learners are not routinely well trained in outpatient care.

These models aren't formally part of educational practice. ... Everybody talks about how the future of medicine is outpatient, but that's not the way [doctors are] necessarily being trained. (GIM 13)

Second, teachers do not traditionally practise within an interprofessional care model, which leaves trainees without the necessary role models. Third, participants described the TIP Program as a model for learning how to care for patients with multimorbidity within the community. They expressed how being a learner on the TIP Program's interprofessional teams was relevant for trainees across different disciplines, and, as such, learners were actively engaged in the program during their rotations. 
Table 2: Quotes illustrating themes

\begin{tabular}{l}
\hline Theme \\
\hline $\begin{array}{l}\text { 1. Creating new perspectives on care } \\
\text { for multimorbidity by sharing } \\
\text { knowledge, skills and attitudes }\end{array}$
\end{tabular}

Representative quotes

for multimorbidity by sharing

knowledge, skills and attitudes

You see what the other people are thinking of — the different styles. (Psych 06)

It just validates that there's a lot of different perspectives to look at. .... So I think it educates the group in that way and models this need to think of what different things are going on. (Psych 06)

There's an added value by far ... because [the patients] have multiple things going on, social, functional, cognitive, medical. It really is useful having that full interdisciplinary team for these particular patients. (Geri 04)

When I get the case summary and then I hear input from an internist or a family doctor - oh wow, that was interesting! I wonder why that hadn't been addressed or that's a wrinkle I certainly didn't think of before. (Psych 05)

I think the greatest benefit is that, because we're all sitting down together at the same table, we can talk about how these things interact and intersect. So, for example, pharmacy can talk about adverse drug interactions that may be contributing to mental illness or making it worse. And then together with social work at the table we can all comment on how we think this is impacting activities of daily living. (GIM 09)

I think there's something synergistic about having all those people together, and you can build on each other's thoughts and possible avenues. (FP 02)

You really need people who have the skills in their discipline at a very high level. (GIM 13)

2. Moving away from a consultant model to an interprofessional team model
I think the family doctors feel very well respected by the specialists, and the specialists are always very supportive in terms of giving ideas that could be readily implemented in primary care. (FP 01)

It takes a special kind of consultant to do this because you're not examining the patient. You can't get a very traditional specialist to do this, because they're really used to having all the i's dotted and the t's crossed. (FP 14)

I'm not going to have everything done as beautifully as I want, but these patients wouldn't have been able to easily get to my clinic otherwise. And if I can provide a little bit of help and support, then at least l'm getting the patient moving in the right direction. (Geri 04)

An internist would want to label a disease, and with this disease comes an investigation and a treatment that is doctor-driven, evidence-base-driven. Whereas with [the TIP Program], it's completely turned around. The treatment, the drug, the investigation will be driven by what the patient wants. (GIM 10)

3. Opportunities for learners
Very few people know how to do interprofessional care; not professionals performing side-byside, but actually interprofessionally. ... Often what's called interprofessional is not; it's still parallel play. (GIM 13)

These trainees in ambulatory care need to be in the community, need to be on interprofessional teams. That's the way of dealing with these very complex patients. (FP 14)

Whether you are a social work student, a medical student, a psychology student, [the TIP Program] allows you to foster that model of interdisciplinary care. (Psych 06)

Note: $\mathrm{FP}$ = family physician, GIM = general internal medicine, Geri = geriatrician, Psych = psychiatrist.

\section{Interpretation}

The study illuminated 3 main themes: creating new perspectives on care for patients with multimorbidity by sharing knowledge, skills and attitudes; the shift from a consultant model to an interprofessional team model; and opportunities for learners in an interprofessional outpatient team setting.

Our participants felt that the TIP Program facilitates transfer of knowledge, skills and attitudes, which enabled teams to create comprehensive and integrated knowledge in the care for people with multimorbidity. One of the main facilitators appeared to be the synchronous one-time collaboration instead of the traditional asynchronous circulation of patient information among providers. ${ }^{28-30}$ Synergistic interactions improved communication and promoted the development of trust and mutual respect. In this way, the TIP Program overcomes important barriers described in the literature ${ }^{13-15}$ through understanding each other's roles and responsibilities, and timely and appropriate communication. This is consistent with studies describing how interprofessional collaboration fosters a more realistic and relevant view of medicine, providing insight and awareness of each team member's professional possibilities and roles. ${ }^{31-35}$

Participants described a shift from a consultant model to an interprofessional team model, which facilitated specialist practice beyond the clinical expert model. Pype and colleagues ${ }^{28}$ reported that professionals who adopted the role of the clinical expert found it more difficult to assimilate their knowledge in an interprofessional consultation process. Our participants explained how, in the TIP Program, specialists were able to contextualize and relate their expert knowledge to the patient situation by adopting a patient-centred approach focused on 
the person in the community. In keeping with the literature, ${ }^{36-38}$ participants also expressed that a shared responsibility for the patient within the context of shared values focused on patient-centred care was an important facilitator for interprofessional learning.

Our participants described the TIP Program as an important educational opportunity for trainees. Clinical training for patients with multimorbidity is typically hospital-based and single-system-focused, with a strong emphasis on the traditional consultation model. The TIP Program provides a model to address the current lack of established methods for trainees to learn interprofessional collaboration across the primary-secondary-tertiary care divide..$^{22,39-43}$ Consequently, the TIP Program can provide opportunities for trainees to move beyond the traditional consultant model and actively participate in interprofessional teamwork. Furthermore, the specialist physicians participating in the TIP Program provide a role model for successful interprofessional collaborations and, as such, provide learners exposure to a real-world model for caring for people with multimorbidity in the primary care context. Adult learning theory supports this teaching methodology. ${ }^{44}$

The success of the TIP Program may come from its merger of different methods for teaching and learning through collaboration that have previously been identified in the literature..$^{5-11}$ Ongoing description and evaluation of similar practice-based programs is required to further explore the perceived interprofessional and educational benefits. Further research on the influence of interprofessional collaborative teamwork such as the TIP Program and its impact on patient care and outcomes is required.

\section{Limitations}

Our sample was limited to 1 program composed only of physicians and may not be wholly transferable to another context. However, the experiences may resonate with other physicians in similar programs. An important limitation of this study is that the perceptions of specialist and family physicians were not a predefined research question; rather, the perceived benefits of the TIP Program for interprofessional collaboration across settings emerged spontaneously in the data collection and subsequently in the analysis. Future studies are needed to explore in greater depth the experiences of both specialists and family physicians working collaboratively in an interprofessional team model when caring for patients with multimorbidity. Also, although our participants raised the topic of educational needs of trainees in caring for patients with multimorbidity, we did not explore the perceptions and experiences of learners. Further studies in this area would be valuable.

\section{Conclusion}

Family physicians and specialists participating in a TIP Program believed the program improved their knowledge and skills, while also serving as an effective care delivery strategy. The findings also support that learners require more exposure to nontraditional consultant models in order to care for patients with multimorbidity effectively. The insights gained through the TIP Program can add to the knowledge base of how to care for patients with multimorbidity, while simultaneously supporting the formal and informal training of physicians and learners from all disciplines and at all levels in the management of these patients.

\section{References}

1. Terner M, Reason B, McKeag AM, et al. Chronic conditions more than age drive health system use in Canadian seniors. Healthc Q 2011;14:19-22.

2. Jansen D, Spreeuwenberg P, Heijmans M. Developments in the care of the chronically ill. Reporting 2012 [report in Dutch]. Utrecht: Nivel; 2012.

3. Adeniji C, Kenning C, Coventry P, et al. What are the core predictors of 'hassles' among patients with multimorbidity in primary care? A cross sectional study. BMC Health Serv Res 2015;15:255.

4. Xyrichis A, Lowton K. What fosters or prevents interprofessional teamworking in primary and community care? A literature review. Int 7 Nurs Stud 2008;45: 140-53.

5. Mickan SM. Evaluating the effectiveness of health care teams. Aust Health Rev 2005;29:211-7.

6. Barrett J, Curran V, Glynn L, et al. CHSRF synthesis: interprofessional collaboration and quality primary healthcare. Ottawa: Canadian Health Services Research Foundation; 2007:48. Available: https://www.cfhi-fcass.ca/Migrated/PDF/ ResearchReports/CommissionedResearch/SynthesisReport_E_rev4_FINAL.pdf (accessed 2019 Nov. 18).

7. Reeves S, Pelone F, Harrison R, et al. Interprofessional collaboration to improve professional practice and healthcare outcomes. Cochrane Database Syst Rev 2017;(6):CD000072.

8. Kennedy N, Armstrong C, Woodward O, et al. Primary care team working in Ireland: a qualitative exploration of team members' experiences in a new primary care service. Health Soc Care Community 2015;23:362-70.

9. Sommers LS, Marton KI, Barbaccia JC, et al. Physician, nurse and social worker collaboration in primary care for chronically ill seniors. Arch Intern Med 2000;160:1825-33.

10. van Dongen JJ, van Bokhoven MA, Daniëls R, et al. Developing interprofessional care plans in chronic care: a scoping review. BMC Fam Pract 2016;17: 137.

11. Brown JB, Ryan BL, Thorpe C. Processes of patient-centred care in Family Health Teams: a qualitative study. CMA7 Open 2016;4:E271-6.

12. van Dijk-de Vries A, van Dongen JJ, van Bokhoven MA. Sustainable interprofessional teamwork needs a team-friendly healthcare system: experiences from a collaborative Dutch programme. 7 Interprof Care 2017;31:167-9.

13. Gardiner C, Gott M, Ingleton C. Factors supporting good partnership working between generalist and specialist palliative care services: a systematic review. Br 7 Gen Pract 2012;62:e353-62.

14. Dossett LA, Hudson JN, Morris AM, et al. The primary care provider (PCP)cancer specialist relationship: a systematic review and mixed-methods metasynthesis. CA Cancer 7 Clin 2017;67:156-69.

15. Stille CJ, McLaughlin TJ, Primack WA, et al. Determinants and impact of generalist-specialist communication about pediatric outpatient referrals. Pediatrics 2006;118:1341-9.

16. Sampson R, Barbour R, Wilson P. The relationship between GPs and hospital consultants and the implications for patient care: a qualitative study. BMC Fam Pract 2016;17:45.

17. van Schaik SM, O'Brien BC, Almeida SA, et al. Perceptions of interprofessional teamwork in low-acuity settings: a qualitative analysis. Med Educ 2014; 48:583-92.

18. Chang A, Bowen JL, Buranosky RA, et al. Transforming primary care training - patient-centered medical home entrustable professional activities for internal medicine residents. 7 Gen Intern Med 2013;28:801-9.

19. Core competencies for interprofessional collaborative practice: 2016 update. Washington: Interprofessional Education Collaborative; 2016. Available: https://hsc.unm.edu/ipe/resources/ipec-2016-core-competencies.pdf (accessed 2019 Nov. 18).

20. Frank J. The CanMEDS 2005 Physician Competency Framework. Better standards. Better physicians. Better care. Ottawa: Royal College of Physicians and Surgeons of Canada; 2005. Available: http://www.ub.edu/medicina unitateducaciomedica/documentos/CanMeds.pdf (accessed 2019 Nov. 18).

21. Framework for action on interprofessional education and collaborative practice. Geneva: World Health Organization; 2010. Available: http://www.who. int/hrh/resources/framework_action/en/ (accessed 2019 July 30).

22. Meijer LJ, de Groot E, Blaauw-Westerlaken M, et al. Intraprofessional collaboration and learning between specialists and general practitioners during postgraduate training: a qualitative study. BMC Health Serv Res 2016;16:376.

23. Sandelowski M. Whatever happened to qualitative description? Res Nurs Health 2000;23:334-40.

24. Sandelowski M. What's in a name? Qualitative description revisited. Res Nurs Health 2010;33:77-84. 
25. Thorne S. Interpretive description: qualitative research for applied practice. 2 nd ed. New York: Routledge; 2016.

26. Stewart M, Fortin M.; Patient-Centred Innovations for Persons with Multimorbidity Team. Patient-Centred Innovations for Persons with Multimorbidity: funded evaluation protocol. CMA7 Open 2017;5:E365-72.

27. Pariser P, Pham TN, Brown JB, et al. Connecting people with multimorbidity to interprofessional teams using telemedicine. Ann Fam Med 2019;17(Suppl 1): S57-62.

28. Pype P, Mertens F, Wens J, et al. Preparing palliative home care nurses to act as facilitators for physicians' learning: evaluation of a training programme. Palliat Med 2015;29:458-63.

29. Collins F, McCray J. Relationships, learning and team working in UK services for children. F Integr Care 2012;20:39-50.

30. Walters L, Prideaux D, Worley P, et al. Demonstrating the value of longitudinal integrated placements to general practice preceptors. Med Educ 2011;45:455-63.

31. Mertens F, de Groot E, Meijer L, et al. Workplace learning through collaboration in primary healthcare: a BEME realist review of what works, for whom and in what circumstances: BEME Guide No. 46. Med Teach 2018;40:117-34.

32. Marshall MN. Qualitative study of educational interaction between general practitioners and specialists. BMF 1998;316:442-5.

33. Kousgaard MB, Thorsen T. Positive experiences with a specialist as facilitator in general practice. Dan Med 7 2012;59:A4443.

34. Allan H, Bryan K, Clawson L, et al. Developing an interprofessional learning culture in primary care. 7 Interprof Care 2005;19:452-64.

35. Carr EC, Worswick L, Wilcock PM, et al. Improving services for back pain: putting the patient at the centre of interprofessional education. Qual Prim Care 2012;20:345-53.

36. Jones A. Some benefits experienced by hospice nurses from group clinical supervision. Eur 7 Cancer Care (Engl) 2003;12:224-32.

37. Bunniss S, Kelly DR. 'The unknown becomes the known': collective learning and change in primary care teams. Med Educ 2008;42:1185-94.

38. Stewart M, Brown JB, Weston W, et al. Patient-centered medicine: transforming the clinical method. 3rd ed. London (UK): Radcliffe Publishing; 2014.

39. Guirguis-Younger M, McNeil R, Runnels V. Learning and knowledgeintegration strategies of nurses and client care workers serving homeless persons. Can 7 Nurs Res 2009;41:21-34.

40. Leasure EL, Jones RR, Meade LB, et al. There is no $\mathrm{i}$ in teamwork in the patient-centered medical home: defining teamwork competencies for academic practice. Acad Med 2013;88:585-92.

41. Kaminetzky CP, Beste LA, Poppe AP, et al. Implementation of a novel population panel management curriculum among interprofessional health care trainees. BMC Med Educ 2017;17:264.

42. Janssen M, Sagasser MH, Laro EAM, et al. Learning intraprofessional collaboration by participating in a consultation programme: What and how did primary and secondary care trainees learn? BMC Med Educ 2017;17:125.
43. Barker M, Lecce J, Ivanova A, et al. Interprofessional communities of practice in continuing medical education for promoting and sustaining practice change: a prospective cohort study. 7 Contin Educ Health Prof 2018;38:86-93.

44. Taylor DC, Hamdy H. Adult learning theories: implications for learning and teaching in medical education: AMEE Guide No. 83. Med Teach 2013;35: e1561-72.

Affiliations: Department of Family Medicine and Primary Healthcare (Boeckxstaens), Ghent University, Ghent, Belgium; Centre for Studies in Family Medicine (Brown, Reichert, Stewart), Department of Family Medicine, Schulich School of Medicine and Dentistry, Western University, London, Ont.; Department of Medicine (Smith), Toronto East Health Network, Michael Garron Hospital, Toronto, Ont.; Department of Family Medicine and Emergency Medicine (Fortin), Université de Sherbrooke, Sherbrooke, Que.

Contributors: Pauline Boeckxstaens, Judith Brown and Sonja Reichert conceived the study and acquired, analyzed and interpreted the data. Christopher Smith drafted the manuscript. All of the authors contributed to the study design, revised the manuscript critically for important intellectual content, approved the final version to be published and agreed to be accountable for all aspects of the work.

Funding: The Patient-Centred Innovations for Persons with Multimorbidity grant is supported by the Canadian Institutes of Health Research's Community-based Primary Health Care Signature Initiative. Moira Stewart was funded by the Dr. Brian W. Gilbert Canada Research Chair in Primary Health Care Research (2003-2017). Pauline Boeckxstaens was supported by a postdoctoral fellowship at the Universite de Sherbrooke and was a Transdisciplinary Understanding and Training on Research Primary Health Care trainee from April 2016 to March 2017. Sonja Reichert holds the Dr. Brian W. Gilbert Chair in Primary Health Care (2019-2024).

Data sharing: The data are not available for use by other researchers.

Prior presentation: 46th Annual North American Primary Care Research Group Meeting, 2018 Nov. 13, Chicago, Ill.

Supplemental information: For reviewer comments and the original submission of this manuscript, please see www.cmajopen.ca/content/8/2/ E251/suppl/DC1. 